\section{Obs Gyne Review - Journal of Obstetric and Gynecology}

2020 Volume 6 Number 4 July-August

\title{
Preoperative dexamethasone and intraperitoneal bupivacaine for postoperative pain relief
}

\author{
Gayam S. ${ }^{1 *}$, Naduvinakeri K. ${ }^{2}$, Rajagopal M. ${ }^{3}$, Neelima C. \\ DOI: https://doi.org/10.17511/joog.2020.i04.05 \\ 1* Susheela Gayam, Head of Department, Department of Obstetrics and Gynaecology, Vijay Marie Hospital and Educational Society, \\ Hyderabad, Telangana, India. \\ 2 Naduvinakeri K., Registrar, Department of Obstetrics and Gynaecology, Vijay Marie Hospital and Educational Society, Hyderabad, \\ Telangana, India. \\ 3 Meera Rajagopal, Senior Consultant, Department of Obstetrics and Gynaecology, Vijay Marie Hospital and Educational Society, Hyderabad, \\ Telangana, India. \\ 4 Neelima C., Senior Consultant, Department of Obstetrics and Gynaecology, Vijay Marie Hospital and Educational Society, Hyderabad, \\ Telangana, India.
}

Introduction: Remarkable advancement in managing post-operative pain is made using various analgesics. Dexamethasone is a potent anti-inflammatory, analgesic, and anti-emetic agent and readily available, easy to administer, and a safe adjunct for postoperative analgesia. The intraperitoneal use of local anesthetics is known to improve postoperative pain. Objective: To assess the effectiveness of preoperative Dexamethasone combined with intra-peritoneal Bupivacaine for postoperative pain relief following surgery. Material and Methods: A prospective, randomized controlled study was done over a period of one year on 172 women scheduled for elective gynecological surgeries. The study group received Dexamethasone $8 \mathrm{mg}$ IV, 5 minutes prior to induction of anesthesia or before surgical incision, and intra-operatively $30 \mathrm{ml}$ of $0.25 \%$ Bupivacaine intraperitoneally under aseptic precautions. The control group received standard anesthesia as per the routine hospital protocol. Results: It was noted that the mean consumption of analgesic doses was significantly high in group B compared to group A $(3.01 \pm 0.52$ vs $1.46 \pm 0.83 ; p<0.001)$. The mean VRes scores in group A were significantly high compared to group B (2.95 \pm 1.01 vs $0.20 \pm 0.51 ; p<0.001)$. Conclusion: Dexamethasone combined with intra-peritoneal Bupivacaine is highly effective in reducing postoperative pain along with PONV.

Keywords: Preoperative Dexamethasone, Intraperitoneal Bupivacaine, Post-Operative pain relief

Corresponding Author

Susheela Gayam, Head of Department, Department of Obstetrics and Gynaecology, Vijay Marie Hospital and Educational Society, Hyderabad, Telangana, India.

Email: sushgayam@yahoo.com
How to Cite this Article

Gayam S, Naduvinakeri K, Rajagopal M, Neelima C. Preoperative dexamethasone and intraperitoneal bupivacaine for postoperative pain relief. Obs Gyne Review J Obstet Gynecol. 2020;6(4):96-101.

Available From

https://obstetrics.medresearch.in/index.php/joog/art icle/view/119
To Browse

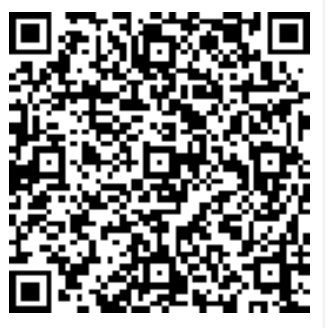

Manuscript Received 2020-08-04

Conflict of Interest No
Review Round 1 2020-08-16

Funding

Review Round 2
$2020-08-23$
Ethical Approval
Yes

Review Round 3

Plagiarism X-checker $8 \%$
Accepted 2020-08-26

Note

(C) 2020 by Susheela Gayam, Naduvinakeri K., Meera Rajagopal, Neelima C. and Published by Siddharth Health Research and Social Welfare Society. This is an Open Access article licensed under a Creative Commons Attribution 4.0 International License https://creativecommons.org/licenses/by/4.0/ unported [CC BY 4.0]. 


\section{Introduction}

Pain is not just a sensory modality but an experience. A taskforce on the taxonomy of the International Association for the Study of Pain (IASP) says that pain is an unpleasant sensory and emotional experience associated with actual or potential tissue damage [1]. Persistent pain after major abdominal surgery can lead to shallow breathing which facilitates retention of secretion with the eventual development of pneumonia contributing to prolonged convalescence.

Therefore, ineffective postoperative pain management has physiological, psychological, ethical, and financial consequences [2]. Postoperative pain not only affects the patients' operative outcome, well being, and satisfaction from medical care, but also directly affects the development of tachycardia, hyperventilation, decrease in alveolar ventilation, a transition to chronic pain, poor wound healing, and insomnia, which in turn may impact the operative outcomes [3].

Pain perception is multifactorial and a complex mixture of neural interactions that start with tissue damage leading to activation of the ascending and descending systems and a chain of events begins that involves both electrical and chemical activities. It is also activated by the influence of psychological and environmental factors [4].

Remarkable advancement in post-operative pain management has been made in the past decades. The multimodal approach has become the norm, involving the use of various classes of analgesic agents. Analgesia groups include; opioids, nonsteroidal anti-inflammatory drugs (NSAIDs), local anesthetic agents, N-methyl-D aspartic acid (NMDA) receptor antagonists (e.g. Ketamine), Magnesium, Steroids (particularly Dexamethasone), Acetaminophen (Paracetamol), as well as nonpharmacologic techniques.

Several studies have shown that steroids, particularly Dexamethasone intravenously (IV) or intrathecally when administered in various doses reduced the pain, pain intensity, Morphine/Pethidine consumption, and nausea and vomiting postoperatively [5].

Dexamethasone is effective in pain reduction after surgery [6]. The preemptive intravenous and intraperitoneal application of local anesthetics is known to improve the postoperative outcome in
Abdominal surgery [7]. However, there is a lack of consensus regarding the drug, dose, concentration, site, and route of administration. Infiltration of local anesthetics (LAs) into surgical wounds is a simple method to provide postoperative analgesia. The basic concept of this technique is to block pain at the origin due to the local application of anesthetics.

LAs block voltage-gated sodium channels and as a consequence, the transmission of pain from the surgical wound is reduced or abolished. In addition, the inflammatory response to the injury is suppressed [8] Bupivacaine, an Amide local anesthetic is the most frequently used local anesthetic agent. Corticosteroids suppress ectopic neuronal discharge.

Perineural injection of glucocorticoid along with local anesthetics is reported to influence the onset and duration of sensory and motor block [9].

\section{Material and Methods}

A hospital-based controlled trial was conducted from September 2018 to April 2019 on172 women scheduled for elective gynecological surgeries at a tertiary care hospital. Patients were divided into two groups of 86 each, group A (study group) and group B (control group). Patients with ASA physical status I (Normal healthy patient), ASA physical status II (Patient with the mild systemic disease) Age $<60$ years, BMI < 35 were included in the study.

Patients with a history of allergy to NSAIDS, having stomach ulcers, Diabetes Mellitus, Cardiovascular Disease, Hepatic cirrhosis, Renal failure, Leucocytosis or leucopenia, Fever (temperature above $37.8^{\circ} \mathrm{C}$ ), Genital Malignancy, use of NSAIDs or Corticosteroids (last $<2$ days before surgery), current opioid use was excluded from the study.

Prior to the commencement, the Ethical Clearance was obtained from the Institutional Ethics Committee. Patients fulfilling selection criteria were detailed about the nature of the study and written informed consent was obtained. The eligible women were interviewed and the demographic data such as age, presenting complaints along with medical and obstetric history were obtained.

The patients were subjected to thorough general, abdominal, local, and pelvic examination, and the type of surgical procedure was noted. Patients were explained regarding the use of the visual analog scale (VAS). These findings were recorded on a predesigned proforma. 
On arrival in the operating room, standard anesthetics, analgesics, and antiemetic were administered in all the cases. Patients were divided into two groups, group A (study group) and group $B$ (control group) each containing 86 patients. Group A (Study group) women in this group received Dexamethasone $8 \mathrm{mg}$ IV, 5 minutes pre-induction of anesthesia, or before surgical incision and intraoperatively received $30 \mathrm{ml}$ of $0.25 \%$ Bupivacaine as intraperitoneal infiltration under aseptic precautions.

Group B (Control Group) women in this group received standard anesthesia as per the routine hospital protocol and no additional intervention for pain management was given.

After completion of the surgical procedure, all patients were transferred to the post-operative care unit. Patients were monitored for vitals (pulse, blood pressure, respiratory rate) and pain and postoperative nausea and vomiting episodes. The pain was assessed using a Visual Analogue Score (VAS) ranging from 0 to 10 . A visual analog scale was explained to the patient during the preoperative visit considering zero as no pain and 10 as a maximum pain point.

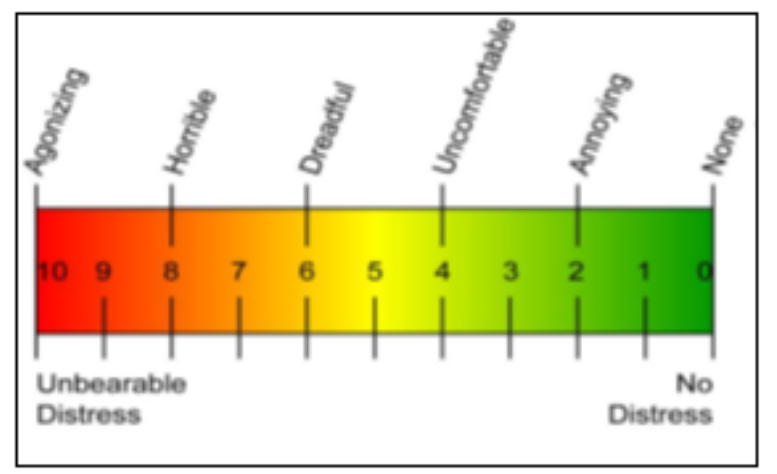

\section{Fig-1: Visual analog scale.}

The VAS score $\leq 4$ was regarded as satisfactory whereas patients reporting a VAS score of $>4$ were administered for rescue analgesia with Inj.Ketorolac $30 \mathrm{mg}$ IM as rescue analgesia. Pain scores were evaluated at an immediate postoperative period, 5 minutes, 1 hour, 4 hours, 8 hours, 12 hours, 16 hours, and 24 hours postoperatively.

The occurrence of side effects like nausea and vomiting was evaluated. The severity of postoperative nausea and vomiting (PONV) was graded on a four-point ordinal scale: 0-no nausea or vomiting, 1- mild nausea, 2- moderate nausea, and 3- severe nausea and vomiting. The rescue
Antiemetic Inj. Ondansetron 4mg IV was given to patients with PONV of grade $>2$. At the end of the 24-hour assessment period, patients were asked to make a global rating of their satisfaction with their post-operative pain management and document the same on the 'Verbal Response (VReS) patient's form. The scores ranged from 0-4, corresponding to poor, fair, good, very good, and excellent satisfaction.

\section{Results}

The categorical data were expressed as rates, ratios, and percentages, and comparison was done using Fishers exact test and chi-square test. The data were analyzed using SPSS statistical software version 20.0. In the present study, most of the women were aged between 21 to 30 years in group A (34.88\%) as well as in group B (38.37\%).

However, the age distribution pattern in group $A$ and group $B$ was comparable $(p=0.608)$. In this study, most of the women had normal body mass index in group A and group B (58.14\% vs $62.79 \%$; $p=0.180)$.

In this study, most of the women belonged to ASA grade $I$ in group A and group B (68.60\% vs $75.58 \% ; p=0.198)$. In this study it was observed that significantly higher number of women in group B complained of VAS $>4$ at one hour ( $0 \%$ vs $37.21 \%$; $p<0.001)$, four hours $(13.95 \%$ vs $53.49 \%$; $\mathrm{p}<0.001), 12$ hours ( $16.28 \%$ vs $45.35 \% ; \mathrm{p}=0.005)$ and 24 hours ( $54.65 \%$ vs $83.72 \%$; $<<0.001)$.

Table-1: Comparison of VAS at Different Interval.

\begin{tabular}{|l|l|l|l|l|l|l|}
\hline \multirow{2}{*}{ Intervals } & VAS & \multicolumn{2}{|c|}{ Group A $(\mathbf{n = 8 6})$} & \multicolumn{2}{|c|}{ Group B $(\mathbf{n = 8 6})$} & \multirow{2}{*}{ p value } \\
\cline { 2 - 6 } & & No. & $\%$ & No. & $\%$ & \\
\hline \multirow{3}{*}{ One hour } & $\leq 4$ & 86 & 100.00 & 54 & 62.79 & \multirow{2}{*}{$<0.001$} \\
\cline { 2 - 6 } & $>4$ & 0 & 0.00 & 32 & 37.21 & \\
\hline \multirow{3}{*}{ Four hour } & $\leq 4$ & 74 & 86.05 & 40 & 46.51 & $<0.001$ \\
\cline { 2 - 6 } & $>4$ & 12 & 13.95 & 46 & 53.49 & \\
\hline \multirow{3}{*}{24 hours } & $\leq 4$ & 72 & 83.72 & 47 & 54.65 & \multirow{2}{*}{0.005} \\
\cline { 2 - 6 } & $>4$ & 14 & 16.28 & 39 & 45.35 & \\
\hline & $>4$ & 39 & 45.35 & 14 & 16.28 & $<0.001$ \\
\cline { 2 - 6 } & $>4$ & 54.65 & 72 & 83.72 & \\
\hline
\end{tabular}

In this study significantly higher number of women in group B had PONV score of $>2$ at one hour (96.51\% vs $59.30 \% ; p<0.001)$, four hours $(94.19 \%$ vs $70.93 \% ; p<0.001)$, eight hours $(90.70 \%$ vs $68.60 \% ; \mathrm{p}<0.001)$ and 12 hours $(97.67 \%$ vs $86.05 \% ; p=0.005$. 
Table-2: Comparison of PONV Episodes at different intervals.

\begin{tabular}{|c|c|c|c|c|c|c|}
\hline \multirow[t]{2}{*}{ Intervals } & \multirow[t]{2}{*}{ PONV Score } & \multicolumn{2}{|c|}{ Group A $(n=86)$} & \multicolumn{2}{|c|}{ Group B $(n=86)$} & \multirow[t]{2}{*}{$p$ value } \\
\hline & & No. & $\%$ & No. & $\%$ & \\
\hline \multirow[t]{2}{*}{ One hour } & $\leq 2$ & 3 & 3.49 & 35 & 40.70 & \multirow[t]{2}{*}{$\mid<0.001$} \\
\hline & $>2$ & 83 & 96.51 & 51 & 59.30 & \\
\hline \multirow[t]{2}{*}{ Four hour } & $\leq 2$ & 5 & 5.81 & 25 & 29.07 & \multirow[t]{2}{*}{$<0.001$} \\
\hline & $>2$ & 81 & 94.19 & 61 & 70.93 & \\
\hline \multirow[t]{2}{*}{ Eight hours } & $\leq 2$ & 8 & 9.30 & 27 & 31.40 & \multirow[t]{2}{*}{$<0.001$} \\
\hline & $>2$ & 78 & 90.70 & 59 & 68.60 & \\
\hline \multirow[t]{2}{*}{12 hours } & $\leq 2$ & 2 & 2.33 & 12 & 13.95 & \multirow[t]{2}{*}{0.005} \\
\hline & $>2$ & 84 & 97.67 & 74 & 86.05 & \\
\hline
\end{tabular}

In this study significantly higher number of women in group $B$ required injection of Ondanseton at one hour $(95.35 \%$ vs $58.14 \% ; \mathrm{p}<0.001)$, four hours $(94.19 \%$ vs $72.09 \% ; \mathrm{p}<0.001)$, eight hours $(90.70 \%$ vs $67.44 \% ; p<0.001)$ and 12 hours (94.19\% vs $95.35 \% ; p=0.001)$.

Table-3: Comparison of the requirement of Ondansetron.

\begin{tabular}{|c|c|c|c|c|c|c|}
\hline \multirow[t]{2}{*}{ Intervals } & \multirow[t]{2}{*}{ Requirement } & \multicolumn{2}{|c|}{ Group A $(n=86)$} & \multicolumn{2}{|c|}{ Group B $(n=86)$} & \multirow[t]{2}{*}{$\mathrm{p}$ value } \\
\hline & & No. & $\%$ & No. & $\%$ & \\
\hline \multirow[t]{2}{*}{ One hour } & Yes & 4 & 4.65 & 36 & 41.86 & \multirow[t]{2}{*}{$<0.001$} \\
\hline & No & 82 & 95.35 & 50 & 58.14 & \\
\hline \multirow[t]{2}{*}{ Four hour } & Yes & 5 & 5.81 & 24 & 27.91 & \multirow[t]{2}{*}{$<0.001$} \\
\hline & No & 81 & 94.19 & 62 & 72.09 & \\
\hline \multirow[t]{2}{*}{ Eight hours } & Yes & 8 & 9.30 & 28 & 32.56 & \multirow[t]{2}{*}{$<0.001$} \\
\hline & No & 78 & 90.70 & 58 & 67.44 & \\
\hline \multirow[t]{2}{*}{12 hours } & Yes & 1 & 1.16 & 12 & 13.95 & \multirow[t]{2}{*}{0.001} \\
\hline & No & 85 & 98.84 & 74 & 86.05 & \\
\hline
\end{tabular}

In this study significantly higher number of women in group B required Inj. Ketorolac at one hour ( $0 \%$ vs $37.21 \% ; \mathrm{p}<0.001)$, four hours $(13.95 \%$ vs $53.49 \% ; p<0.001), 12$ hours ( $15.12 \%$ vs $45.35 \%$; $\mathrm{p}=0.001)$ and 24 hours $(54.65 \%$ vs $82.56 \%$; $\mathrm{p}<0.001)$.

Table-4: Comparison of the requirement of Ketorolac.

\begin{tabular}{|c|c|c|c|c|c|c|}
\hline \multirow[t]{2}{*}{ Intervals } & \multirow[t]{2}{*}{ Requirement } & \multicolumn{2}{|c|}{ Group A $(n=86)$} & \multicolumn{2}{|c|}{ Group B $(n=86)$} & \multirow[t]{2}{*}{ p value } \\
\hline & & No. & $\%$ & No. & $\%$ & \\
\hline \multirow[t]{2}{*}{ One hour } & Yes & 0 & 0.00 & 32 & 37.21 & \multirow[t]{2}{*}{$<0.001$} \\
\hline & No & 86 & 100.00 & 54 & 62.79 & \\
\hline \multirow[t]{2}{*}{ Four hour } & Yes & 12 & 13.95 & 46 & 53.49 & \multirow[t]{2}{*}{$<0.001$} \\
\hline & No & 74 & 86.05 & 40 & 46.51 & \\
\hline \multirow[t]{2}{*}{12 hours } & Yes & 13 & 15.12 & 39 & 45.35 & \multirow[t]{2}{*}{0.001} \\
\hline & No & 73 & 84.88 & 47 & 54.65 & \\
\hline \multirow[t]{2}{*}{24 hours } & Yes & 47 & 54.65 & 71 & 82.56 & \multirow[t]{2}{*}{$\mid<0.001$} \\
\hline & No & 39 & 45.35 & 15 & 17.44 & \\
\hline
\end{tabular}

In this study, most of the women in group $A$ that is
$38.37 \%$ and $29.07 \%$ opined excellent and very good satisfaction with post-operative pain management while, in group $B$, the majority of the patients opined poor satisfaction $(83.72 \%)$ with their postoperative pain management and this difference was statistically significant $(p<0.001)$.

Table-5: Comparison of Patient Satisfaction Score (VReS).

\begin{tabular}{|l|l|l|l|l|}
\hline \multirow{2}{*}{ Patient satisfaction score } & \multicolumn{2}{|c|}{ Group A $(\mathbf{n = 8 6})$} & \multicolumn{2}{c|}{ Group B ( $\mathbf{n}=\mathbf{8 6})$} \\
\cline { 2 - 5 } & Number & Percentage & Number & Percentage \\
\hline Poor & 0 & 0.00 & 72 & 83.72 \\
\hline Fair & 9 & 10.47 & 10 & 11.63 \\
\hline Good & 19 & 22.09 & 4 & 4.65 \\
\hline Very good & 25 & 29.07 & 0 & 0.00 \\
\hline Excellent & 33 & 38.37 & 0 & 0.00 \\
\hline Total & 86 & 100.00 & 86 & 100.00 \\
\hline
\end{tabular}

In the present study, the mean VRes scores in group A were significantly high compared to group B (2.95 \pm 1.01 vs $0.20 \pm 0.51 ; p<0.001)$.

\section{Discussion}

Overall the present study highlighted that preoperative Dexamethasone combined with intraperitoneal Bupivacaine is highly effective in reducing post-operative pain compared to standard anesthesia pain management protocol. Also, it is safe and well-tolerated as it is associated with lower postoperative nausea and vomiting (PONV) and consumption of Ondansetron. Furthermore, it provides excellent patient satisfaction.

Goldstein A. et al [10] found that local anesthetic installation at the end of laparoscopy prevents postoperative pain and dramatically decreases the need for morphine. This technique, compared with placebo, is safe, improves patient comfort, shortens the stay in the postoperative care unit, and decreases nursing care in the ward.

However, the authors recommended Ropivacaine rather than Bupivacaine for local anesthetic instillation. Although the observations from the present study are partly in agreement with the study by Goldstein A. et al [10].

The authors reported that the morphine consumption at wake-up and over the first 24 hours was significantly lower $(p<0.05)$ in Bupivacaine $0.5 \%$ (mean, $0.92 \mathrm{mg}$ at wake-up; $3.08 \mathrm{mg}$ over 24 h) and with Ropivacaine $0.75 \%$ (mean, $0.25 \mathrm{mg}$ at wake-up; $0.69 \mathrm{mg}$ over $24 \mathrm{~h}$ ), than saline (mean, $4.18 \mathrm{mg}$ at wake-up; $12.93 \mathrm{mg}$ over $24 \mathrm{~h}$ ). 
The morphine-sparing effect of ropivacaine was significantly greater than that of Bupivacaine. This study recommended that local anesthetics should be instilled in all gynecologic patients at the end of all laparoscopic procedures.

Another double-blind randomized clinical trial by Asgari Z. et al [11] was done to show the efficacy of Intraperitoneal Dexamethasone on relieving shoulder pain after gynecologic laparoscopy.

It was found that the severity of pain in the Dexamethasone group within 0, 2, 4, 8, 12, 24 hours after the procedure was significantly less than in the placebo group $(p<0.001)$.

The average consumption of opioids as analgesic/sedative in the placebo group was more than the Dexamethasone group $(p=0.025)$ and the study concluded that the prescription of $16 \mathrm{mg}$ of Dexamethasone (single dose) in the peritoneal cavity may significantly reduce the severity of pain after Laparoscopy in comparison with placebo and may decrease the need for narcotics as pain relief.

A retrospective cohort study by Rivard C et al [12] to evaluate if the administration of intraperitoneal Bupivacaine decreased postoperative pain in patients undergoing minimally invasive gynecologic and gynecologic cancer surgery reported that, the median patient-reported pain scores were lower on the day of surgery in the intraperitoneal Bupivacaine group (2.7 vs 3.2, $p=0.05$ ) this study showed that, the administration of intraperitoneal Bupivacaine was associated with improved postoperative pain control in patients undergoing minimally invasive gynecologic and gynecologic cancer surgery.

Overall the present study showed that Dexamethasone combined with intra-peritoneal Bupivacaine is highly effective in reducing the postoperative pain along with PONV thereby results in lower analgesic consumption as well as antiemetics after gynecological surgeries in comparison to standard anesthesia protocol.

However, these findings prompt caution in the interpretation due to the potential limitations of this study.

\section{Conclusion}

Based on the findings of this study it may be concluded that Dexamethasone combined with intra-peritoneal Bupivacaine is highly effective in reducing the postoperative pain along with post-
Operative nausea and vomiting (PONV) thereby results in lower analgesic consumption as well as antiemetics after gynecological surgeries in comparison to standard anesthesia protocol.

\section{What does the study add to the existing knowledge}

The current study establishes the effectiveness of Dexamethasone combined with intra-peritoneal Bupivacaine in the reduction of postoperative pain and postoperative nausea and vomiting.

\section{Author's contribution}

Dr. Susheela Gayam: Concept, manuscript
preparation

Dr. Naduvinakeri K.: Data analysis, study design

Dr. Meera Rajagopal: Data collection

Dr. Neelima C.: Manuscript preparation

\section{Reference}

01. Merskey H, AlbeFessard D, Bonica JJ, Carmon A, Dubner R, Kerr FWL, et al. Pain terms- a list with definitions and notes on usage, Recommended by the IASP subcommittee on taxonomy. PAIN. 1979;6(3)249-252.

[Crossref]

02. Ismail S, Siddiqui AS, Rehman A. Postoperative pain management practices and their effectiveness after major gynecological surgeryAn observational study in a tertiary care hospital. J Anaesthesiol Clin Pharmacol. 2018;34(4)478-484.

doi: 10.4103/joacp.JOACP_387_17 [Crossref]

03. Fan $Z R$, Ma J, Ma XL, Wang $Y$, Sun $L$, Wang $Y$, et al. The efficacy of dexamethasone on pain and recovery after total hip arthroplasty- A systematic review and meta-analysis of randomized controlled trials. Med (Baltimore). 2018;97(13)e0100.

doi: $10.1097 / M D .0000000000010100$ [Crossref]

04. Golwala MP, Swadia VN, Dhimar AA, Sridhar NV. Pain relief by dexamethasone as an adjuvant to local anaesthetics in supraclavicular brachial plexus block. J Anaesth Clin Pharmacol. $2009 ; 25(3) 285-288$.

[Crossref] 
05. Bisgaard T, Klarskov B, Kehlet H, Rosenburg J. Pre-operative dexamethasone improves surgical outcome after laproscopic cholecystectomy- a randomized, double-blind placebo-controlled trial. Ann Surgery. 2003;238(5)651-660.

doi: 10.1097/01.sla.0000094390.82352.cb [Crossref]

06. Breivik $\mathrm{H}$. Postoperative pain management- why is it difficult to show that it improves outcome. Eur J Anaesthesiol. 1998;15(6)748-751. doi: 10.1097/00003643-199811000-00022 [Crossref]

07. Kumar S, Palaria U, Sinha AK, Punera DC, Pandey V. Comparative evaluation of ropivacaine and ropivacaine with dexamethasone in supraclavicular brachial plexus block for postoperative analgesia. Anesth Essays Res. 2014;8(2)202-208.

doi: $10.4103 / 0259-1162.134506$ [Crossref]

08. Worner J, Rukwied R, Konrad C. [Co-analgesics today and tomorrow a receptor-based overview of therapeutical options]. Anasthesiologie, Intensivmedizin, Notfallmedizin, Schmerztherapie- AINS. 2009;44(11)736-744. doi: $10.1055 / \mathrm{s}-0029-1242128$ [Crossref]
09. Hudspith MJ. Anatomy, physiology and pharmacology of pain. Anaesthes Intens Care Med. $2019 ; 20(8) 419-425$.

doi: $10.1016 /$ j.mpaic.2016.06.003 [Crossref]

10. Goldstein A, Grimault $P$, Henique A, Keller $M$, Fortin A, Darai E. Preventing postoperative pain by local anesthetic instillation after laparoscopic gynecologic surgery- a placebo-controlled comparison of bupivacaine and ropivacaine. Anesth Analg. 2000;91(2)403-407. doi: 10.1097/00000539-200008000-00032 [Crossref]

11. Asgari Z, Mozafar-Jalali S, Faridi-Tazehkand N, Sabet S. Intraperitoneal dexamethasone as a new method for relieving postoperative shoulder pain after gynecologic laparoscopy. Int J Fertil Steril. 2012;6(1)59-64.

[Crossref]

12. Rivard C, Vogel RI, Teoh D. Effect of Intraperitoneal Bupivacaine on Postoperative Pain in the Gynecologic Oncology Patient. J Minim Invasive Gynecol. 2015;22(7)1260-1265. doi: 10.1016/j.jmig.2015.07.013 [Crossref] 